\title{
De la subalternidad a la ¿autodeterminación identitaria? Disputas discursivas sobre el "ser indígena" en el Ecuador del siglo XX
}

\author{
Vadim Guerrero*
}

\begin{abstract}
RESUMEN

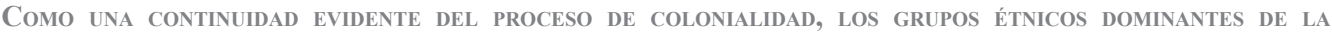
SOCIEDAD ECUATORIANA HAN CONSTRUIDO UNA SERIE DE DISCURSOS SOBRE LA IDENTIDAD INDÍGENA (QUIÉNES SON Y QUE LOS CARACTERIZA); AL MISMO TIEMPO QUE HAN IMPEDIDO, MATERIAL Y SIMBÓLICAMENTE, QUE LOS GRUPOS RACIALIZADOS COMO "INDÍGENAS" SEAN AGENTES DE SU PROPIA AUTODETERMINACIÓN IDENTITARIA. ESTA CONDICIÓN DE SUBALTERNIDAD HA COMENZADO A RESQUEBRAJARSE A PARTIR DE LOS PROCESOS ORGANIZATIVOS QUE HAN LLEVADO A CABO VARIOS GRUPOS INDÍGENAS, EN PARTICULAR AL PROMOVER DISCURSOS DE CORTE ETNICISTAS QUE HAN LOGRADO POSICIONARSE DENTRO DEL CAMPO DE LAS REPRESENTACIONES SOCIALES DOMINANTES Y DISPUTAR EL SENTIDO SOBRE EL "SER INDÍGENA". No OBSTANTE, ESTOS DISCURSOS SE BASAN EN NOCIONES ESENCIALISTAS DE CULTURA Y PROMUEVEN LÓGICAS DE HOMOGENIZACIÓN INTERNA, QUE EVIDENCIAN UNA CONTINUIDAD DE LA COLONIALIDAD A PESAR DE LA APARENTE TRANSCENDENCIA DE LA CONDICIÓN DE SUBALTERNIDAD IDENTITARIA.
\end{abstract}

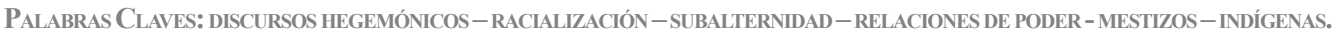

Abstract

AS AN EVIDENT CONTINUITY OF THE COLONIALITY PROCESS, THE DOMINANT ETHNIC GROUPS OF ECUADORIAN SOCIETY HAVE CONSTRUCTED A SERIES OF DISCOURSES ON INDIGENOUS IDENTITY (WHO THEY ARE AND WHAT CHARACTERIZES THEM); AT THE SAME TIME THAT THEY HAVE IMPEDED, MATERIALLY AND SYMBOLICALLY, THAT RACIALIZED GROUPS AS "INDIGENOUS" ARE AGENTS OF THEIR OWN SELF-DETERMINATION IDENTITY. THIS SUBALTERNITY CONDITION HAS BEGUN TO CRUMBLE FROM THE ORGANIZATIONAL PROCESSES THAT HAVE BEEN CARRIED OUT BY VARIOUS INDIGENOUS GROUPS, IN PARTICULAR BY PROMOTING ETHNIC DISCOURSES THAT HAVE MANAGED TO POSITION THEMSELVES WITHIN THE DOMINANT SOCIAL REPRESENTATIONS FIELD AND DISPUTE THE MEANING OF "BE INDIGENOUS" NONETHELESS, THESE DISCOURSES ARE BASED ON ESSENTIALIST CULTURE NOTIONS AND PROMOTE AN INTERNAL HOMOGENIZATION LOGIC, WHICH SHOW A CONTINUITY OF COLONIALITY DESPITE THE APPARENT TRANSCENDENCE OF THE SUBALTERNITY IDENTITY CONDITION.

KEYWORDS: HEGEMONIC DISCOURSES - RACIALIZATION - SUBALTERNITY - POWER RELATIONS - MESTIZOS - INDIGENOUS.

* Licenciado en Antropología Aplicada (Universidad Politécnica Salesiana-Ecuador). Especialista en Epistemologías del Sur (Universidad de Coimbra-Portugal). Master en Investigación en Comunicación, mención Estudios de Recepción Mediática (Universidad Andina Simón Bolívar - Ecuador). Investigador independiente. Correo electrónico: vadimkanhiwara@hotmail.com 


\section{Introducción}

$\mathrm{E}$ n base a la premisa de inspiración saussureana, que plantea que los significantes no se refieren directamente, ni en una relación de exacta correspondencia, a entidades fijas del mundo material o a esencias, sino que producen significado al establecer relaciones (principalmente de oposición, diferencia o semejanza) con otros significantes dentro de un código determinado (Barker, 2003), varios autores, entre ellos Stuart Hall (2003: 18), afirman que la identidad, "sólo puede construirse a través de la relación con el Otro, la relación con lo que él no es, con lo que justamente le falta, con lo que se ha denominado su afuera constitutivo". En efecto, la "mismidad" y la "otredad" constituyen procesos simbólicos que se co-producen simultánea y sistemáticamente, en relación de interdependencia, "a partir de procesos de negociación en el curso de las interacciones cotidianas" (Marcús, 2015: 108), pero enmarcadas en contextos sociopolíticos específicos. De ahí que los significados de "mismidad" y "otredad", si bien pueden ser estabilizados temporalmente, son susceptibles a cambios, y por lo tanto no pueden ser fijados o cerrados totalmente (Hall, 2010).

En concordancia con los estudios post y decoloniales, consideramos que las identidades se construyen dentro de contextos atravesados y estructurados por relaciones de poder, dominio y hegemonía; por lo que el proceso simbólico en el que se da sentido a la "mismidad" y a la "otredad" implica un ejercicio de distinción y jerarquización en el que "cada identidad depende de la posición en la que se encuentra cada grupo social en relación a otro" (Fraga, 2013: 391). De ahí que, desde estas perspectivas, se hable de la existencia de "identidades hegemónicas" e "identidades subalternas" que se coproducen simultáneamente (Ibíd.).

De acuerdo con Gayatri Spivak (2003: 298), la subalternidad constituye la condición "en la cual un sujeto no ocupa una posición discursiva desde la que pueda hablar o responder", es decir su lugar de enunciación carece de los medios para que sus discursos ocupen un lugar dentro del campo de las representaciones sociales dominantes. En esta línea, las identidades se construirían, entre otros factores, sobre la base de discursos identitarios o "regímenes de representación" (Hall, 2010) institucionalizados previamente. Por tanto, analizar la construcción identitaria de un grupo social subalterno implica estudiar los discursos dominantes que se han institucionalizado sobre este grupo y los mecanismos que han permitido su hegemonización. No obstante, así como "el sujeto colonizado subalterno es irremediablemente heterogéneo" (Spivak, 2003: 322) los sistemas de representación que intentan definirlo también lo son. De ahí la necesidad de estudiar la disputa por el sentido sobre la "mismidad-otredad" dentro de su particular desarrollo histórico, cultural y político ${ }^{1}$.

La paradoja de la subalternidad consiste en que una vez que el subalterno logra hacer que "su voz se escuche", deja en ese mismo momento de ser subalterno. No obstante, "la salida de la condición de subalternidad es también una entrada al sistema discursivo dominante o hegemónico" (Spivak, 1999, en: Fraga, 2013: 398), en tanto es necesario optar, al menos en parte, por los mecanismos dominantes de comunicación y algunas de sus lógicas discursivas, a fin de que sus discursos y autorepresentaciones logren posicionarse dentro del campo de las representaciones sociales dominantes y así luchar por la hegemonía del sentido (Ibíd.).

A partir de estas premisas teóricas, el presente artículo pretende realizar, en un primer momento, una breve genealogía de los discursos hegemónicos y los mecanismos que han logrado imponer la condición de subalternidad a los sujetos que, en Ecuador, han sido racializados como indígenas. Esta genealogía se realizará mediante una sistematización y discusión de fuentes bibliográficas y estudios previos. Posteriormente se analizará los

1 Así por ejemplo, en determinadas condiciones históricas y socioculturales, presentes sobre todo en sociedades organizadas en base a una matriz colonial, es posible evidenciar grupos que han acaparado los mecanismos de poder simbólico-cultural, lo cual les permite imponer identidades a los grupos subalternizados, quienes a su vez carecen de los recursos y mecanismos para escapar de estos imaginarios, "corriendo el riesgo de no existir sino en los estereotipos negativos impuestos por los demás” (Dubet, 1987: 528). 
discursos y acciones etnicistas de los movimientos indígenas en el marco de las relaciones que han establecido con el Estado ecuatoriano, a fin de determinar si efectivamente existe una ruptura -o una continuidad- de la condición de subalternidad del indígena en su dimensión étnica-identitaria ${ }^{2}$.

\section{La subalternización de la identidad indígena}

En los primeros años de la república del Ecuador, gran parte de las leyes, instituciones e imaginarios hegemónicos sobre el indígena, presentes en la época colonial, se mantuvieron sin mayores cambios. Así, por ejemplo, continuó estando vigente el tributo indígena; por una parte porque constituía un importante rubro del presupuesto estatal (Guerrero, 1994), pero además porque permitía una clara delimitación entre los grupos racializados de la época: los indígenas fueron definidos como "indios tributarios" en contraposición con los "ciudadanos", en donde cabían tanto blancos como mestizos (Ibarra, 1999; Guerrero, 1994). Por tanto, en el discurso oficial de la República continuó estando vigente aquella diferenciación racista colonial propia del sistema de castas, así como la definición del estatus del indígena desde una perspectiva eclesiástica y jurídica, a través de la "concurrencia de tres categorías coloniales: el estado de rústico, de persona miserable y de menor de edad" (Chávez, 2008: 229) .

Además, el grueso de las instituciones coloniales, articuladas desde finales de la época colonial dentro del sistema hacendatario, continuaron siendo las principales instituciones del sistema socioeconómico en la temprana república (Ibarra, 1999). Por tanto, tal como lo menciona Andrés Guerrero (1993: 95) "casi todo el multifacético sistema de gobierno colonial de la República de los Indios que permitió durante tres siglos la administración étnica fue incorporado al flamante Estado-nación con algunas variaciones y adaptaciones".

No fue sino hasta mediados del siglo XIX con la supresión del tributo indígena, su consideración como "ciudadanos"4, su ingreso a los catastros y la delegación de su administración a los poderes locales y privados ${ }^{5}$, cuando las relaciones entre indígenas y el Estado comenzaron a cambiar, aunque no necesariamente para mejor. Y es que, a pesar de estos cambios, la condición subalterna del indígena dentro de las relaciones coloniales de poder, así como los discursos e imaginarios discriminatorios que sustentaban estas relaciones, continuaron perpetuándose por mucho tiempo más.

Tanto la nueva administración étnica como la ampliación de la ciudadanía a los indígenas, produjo un profundo proceso de invisibilización hacia este grupo dentro de la esfera públicapolítica, proceso que se prolongó hasta mediados del siglo XX. Y es que, los indígenas, en efecto, "desaparecieron de todos los registros centrales del Estado: de las leyes, censos de población, presupuestos del estado, informes de ministros y gobernadores y de la correspondencia entre las

2 Cabe mencionar que, si bien la subalternización de estos grupos se remonta a la época colonial -tal como los estudios decoloniales lo han demostrado en varias investigaciones- por motivos de espacio hemos delimitado nuestra unidad de análisis al siglo XX.

3 "La rusticidad es la falta de participación en la cultura letrada. Los rústicos podían guiarse en materias privadas conforme a sus costumbres. Es miserable quien no valiéndose por sí mismo socialmente, requería de un amparo especial (indígenas, huérfanos, viudas). El menor de edad tenía una limitación de la razón humana y no era gente de razón plena. Esta categorización produce un verdadero estatus de etnia" (Chávez, 2008: 229).

4 Cabe precisar que se trató de una "supuesta" ciudadanía, ya que los indígenas, así como los afrodescendientes y otros grupos subalternos, quedaron al margen de muchos de los derechos fundamentales. Por ejemplo, del derecho al voto hasta 1979. Además, la ciudadanía tenía restricciones en cuanto al género femenino, las edades, fortunas y situaciones de dependencia laboral (Guerrero, 1994). Según Andrés Guerrero (1998: 119), "la ciudadanía en el Ecuador se construye a lo largo del siglo XIX como un campo de dominación donde se juega la exclusión de poblaciones".

5 En efecto, el naciente Estado ecuatoriano, "en un acto de omisión antes que una política estatal" (Guerrero, 1994: 201), delegó la administración y gestión demográfica, económica, espacial y simbólica de las poblaciones indígenas a "un organismo multiforme, heterogéneo y privado: fue entregada a los poderes locales (...) conformados por las haciendas y la iglesia parroquial, los consejos municipales y los funcionarios del Estado, los mediadores étnicos y los vínculos personales -económicos y rituales- entre 'blancos de pueblo' y comuneros" (Ibíd.). De esta manera, la "administración étnica" pasó de ser un "hecho público" a un "hecho privado" (Ibíd.). 
autoridades superiores" (Guerrero, 1994: 214-215). No obstante, el proceso de construcción de la identidad nacional mestiza -proceso característico sobre todo desde finales del siglo XIX ${ }^{6}$ necesitó de la imagen del "indio" para su concreción.

Principalmente, con el advenimiento de las ideas liberales, las élites políticas adoptaron el concepto de Estado- Nación culturalmente homogéneo de Europa y el mestizaje se postuló como el discurso oficial de la nacionalidad ecuatoriana. Sin embargo, como lo mencionan Carlos de la Torre y Patrick Hollenstein (2001: 11):

"El discurso del mestizaje, si bien invitaba a todos a ser parte de la nacionalidad, negaba las especificidades culturales de los no blancos. Si bien se reconocía que los indígenas eran parte de la nación, en especial por su pasado glorioso, se los representaba como individuos totalmente explotados e incivilizados en el presente. Las narrativas del mestizaje monocultural contribuyeron a la creación de un orden ideológico que situó a los blanco-mestizos en los espacios urbanos como los portadores de la civilización y la modernidad. Los descendientes de los esclavos africanos y de los indígenas fueron localizados en los márgenes de la nación y en los espacios donde reinaba el primitivismo. El rol de los blanco-mestizos fue muy claro: civilizar y blanquear a los no blancos".

De tal manera, el mestizaje fue propuesto a partir de una lógica binaria eurocéntrica, que caracterizaría al "uno, como universal, canónico, "neutral" y, a su otro, como resto, sobra, anomalía, margen; siendo así clausurados los tránsitos, la disponibilidad para la circulación entre las posiciones, que pasan a ser todas colonizadas por la lógica binaria" (Segato, 2011: 23). En concordancia con Fredy Rivera o Blanca Muratorio (1998: 58), el "indio" fue convertido en la "contra-imagen del proyecto de ciudadanía blanco mestiza", es decir en el "afuera constitutivo" de la identidad criolla-mestiza ecuatoriana?.

Pero además, la apuesta por el mestizaje como política identitaria del Estado Ecuatoriano estuvo sustentada en un conjunto de representaciones excluyentes o paternalistas sobre los «otros». Así, "para lograr concretar el proyecto e idea de nación criolla-mestiza se desarrollaron una serie de nociones y representaciones paternalistas, indigenistas y neoindigenistas" (Rivera, 1998: 59), representaciones que todavía siguen estando presentes en el campo discursivo actual.

A finales del siglo XIX, en el Ecuador se desarrolló una nueva corriente política y de pensamiento, denominada liberalismo, la cual se contrapuso al pensamiento conservador de los tradicionales sectores dominantes (terratenientes de la sierra principalmente). Se perfilaban, en aquel entonces, dos posiciones antagónicas: “el pensamiento liberal que luego desembocó en el radicalismo y, el pensamiento conservador que introduciendo algunos cambios continuó con un pensamiento fuertemente legitimador de la sociedad tradicional, religiosa y latifundista" (Ribadeneira, 2001: 56). En este contexto, "el indio real se convirtió en peón semiótico en la lucha entre dos hegemonías: la conservadora liderada por la Iglesia y el liberalismo radical, en un momento crítico en la conformación del Ecuador como estado-nación moderno" (Muratorio, 2003: 369).

El liberalismo llegó al poder en 1895 a través de la Revolución Liberal liderada por Eloy Alfaro. La Revolución generó una serie de reformas a nivel político, económico y social, entre las que se destacan la implementación del laicismo, el establecimiento de la educación pública y obligatoria, la libertad de cultos, la creación del registro civil y la promulgación de las leyes de

6 Muratorio (1994) menciona que desde la etapa denominada "progresismo", comprendida entre 1884-1895, y más aún en el liberalismo se fomentó la idea del Ecuador como una nación diferenciada con una identidad propia.

7 Según Fredy Rivera (1998), este fenómeno identitario es común en gran parte de los Estados-Nación latinoamericanos, puesto que "desde los momentos iniciales o fundacionales de varios estados-nación latinoamericanos se presentó un proceso de construcción nacional que contiene un complejo juego de representaciones e imaginarios sobre los diferentes, los indios" (Ibíd.: 57). 
matrimonio civil y divorcio, entre otras. En cuanto a la población indígena, el Estado se atribuyó la función de "protector de la raza oprimida" (Guerrero, 1994) y promovió un discurso de justicia para el "indio"8 (Ibarra, 2003). No obstante, el sector indígena no se vio mayormente favorecido por las reformas liberales. Por una parte, "el Estado de la Revolución Liberal no eliminó ni substituyó al poder local como administrador étnico. Menos aún pretendió suprimir la división de facto entre ciudadanos blancos y sujetos indios" (Guerrero, 1993: 97). Entre tanto, a pesar de la abolición legal del concertaje en 1897 y la intención de tomar medidas tendientes a llevar mano de obra indígena hacia las haciendas cacaoteras de la costa, no se logró abolir de manera definitiva el trabajo servil en las haciendas serranas y más bien "aumentó el asedio y usurpación terrateniente sobre los recursos comunales de campesinos que aún los detentaban, así como las tasas de explotación ejercidas en contra de las unidades campesinas insertas en las haciendas" (Almeida, 1990: 171).

A nivel discursivo, el liberalismo, a fin de dar una explicación científica de la sociedad y de los indígenas, acogió varios principios de la teoría evolucionista, hegemónica en aquel entonces dentro de las nacientes ciencias sociales, cuya idea central planteaba que toda sociedad transcurre por una serie de etapas sucesivas y graduales (salvajismo-barbariecivilización), que evidencian el grado de evolución de la misma. Desde esta perspectiva, el indígena fue visto como un "sujeto irracional por medio de la fórmula: indios=barbarie=ani malidad=pasividad irracional, ante el cual valen todos los esfuerzos civilizatorios de lengua castiza y cultura ecuatoriana" (Rivera, 1998: 59). Por lo tanto, la imagen que sobre el Ecuador se pretendía construir era, precisamente, "la de la salida de esa barbarie y su triunfal entrada en la civilización, para lo cual debía ser escondido al otro, al indígena, pues su verdadera imagen no correspondía con la civilización sino que más bien se acercaba a la de la barbarie" (Ribadeneira, 2001: 55).

Además, el discurso liberal culpó a la iglesia y a los gobiernos conservadores de la situación "degradante" del indígena. Por ejemplo, Abelardo Moncayo, uno de los principales gestores del liberalismo, recurre a la imagen del indígena "como un ser desgraciado debido a la opresión de la que han sido objeto por parte del poder conservador y terrateniente; así términos como degradación, indolencia, tristeza, brutalidad, desconfianza, timidez, superstición, ignorancia, son utilizados para describirlo" (Ribadeneira, 2001: 58).

De tal manera, las representaciones negativas sobre el indígena se convirtieron en uno de los argumentos más importantes del liberalismo para justificar su lucha contra los gobiernos conservadores. Al igual que Simón Bolívar, quien en la época de la independencia había culpado a la corona española de la situación denigrante del indígena, esta vez, los liberales señalaban a la administración conservadora y la iglesia como los supuestos responsables de la situación del indio. En los dos casos, la imagen del indio sirvió para justificar los intereses de los grupos que pugnan el poder y no los intereses de los indígenas como tal. En ese sentido, es evidente la continuidad de la condición de subalternidad del indígena, a pesar del cambio ideológico en las élites políticas.

Igualmente, las nuevas élites liberales postularon un discurso sobre el mestizaje que, similar al discurso de la ilustración iberoamericana y de la independencia ${ }^{9}$, incluía una imagen mitologizada del pasado indígena, representándolo como aristocrático y noble, al mismo tiempo que rechazaba totalmente su presente. Los indios "reales" y actuales eran representados como sujetos degradados e incapaces de determinar lo que les es conveniente de lo que no (Muratorio,

8 De hecho, las constituciones de 1906 y 1929 establecen que "los poderes públicos deberán protección a la raza india en orden a su mejoramiento en la vida social" (Chávez, 2008: 230).

9 El discurso de la ilustración hispanoamericana está representado en el caso de Ecuador por autores como Eugenio Espejo o Juan de Velasco, discursos que tuvieron un fuerte impacto a finales del siglo XVIII. Entre tanto, por "discurso de la independencia" nos referimos particularmente al discurso de Simón Bolívar. 
1994). Por tal razón, el mestizaje aceptado y promovido era entre el "blanco moderno y actual" y el "indio aristocrático" del pasado; es decir un discurso ficcional e imposible de mestizaje. En ese sentido, como lo menciona Blanca Muratorio (1994: 177), el liberalismo:

\begin{abstract}
"Usó a los Indios como "peones semióticos" para sus propios intereses iconográficos y para legitimar sus propios éxitos económicos. En este proceso también empezó a construir una imagen del Ecuador como Ser colectivo. En este sistema dominante de representación, la imagen del mestizaje emerge como una "ficción maestra" construida en un proceso dialéctico de exclusión e inclusión del Otro indígena".
\end{abstract}

Posteriormente, a partir de 1920 los indígenas fueron un tema recurrente en la literatura, el arte y las ciencias sociales ecuatorianas. Si antes, la gran mayoría de los estudios acerca de los "indios" fueron escritos por abogados y juristas, en este periodo resaltaron los trabajos e investigaciones realizadas, principalmente, por antropólogos, sociólogos y médicos de salud pública, quienes tuvieron una fuerte incidencia en los círculos artísticos, académicos y políticos del país ${ }^{10}$ (Clark, 1999). Se conformará, desde entonces, la corriente de pensamiento que se conoce como "indigenismo"11, representada por reconocidos pensadores como Pio Jaramillo Alvarado, Pablo Arturo Suarez, Jorge Icaza, Antonio Santiana, Carlos Andrade Marín, Leopoldo Chávez, Alfredo Pérez Guerrero, entre otros (Clark, 1999).

Para comprender el indigenismo, es necesario primeramente mencionar que entre los años veinte y cuarenta, una vez que el discurso del desarrollo empezaba a tomar fuerza sobre todo entre los sectores que tendían hacia la industrialización, los indígenas fueron vistos como un "peso muerto" o un "miembro pasivo" del desarrollo nacional, que vivían una "existencia vegetativa" (Ibíd.). Uno de los principales exponentes del indigenismo, Leopoldo Chávez (1943), resumió este tipo de imágenes, antes de argumentar en contra de ellas, de la siguiente manera:
"A menudo se habla de él [el indio] calificándole de "peso muerto" en la vida del país; se afirma dogmáticamente que no es susceptible de cultura y que su mente no es apta para desenvolverse al ritmo de la civilización actual, que su abyección lo ha sumido en el círculo estrecho de la vida vegetativa, que su relajación de costumbres le incapacita para la convivencia social; en fin, que tenemos que soportar su existencia en gracia tan sólo de la recompensa que nos reporta su faena torpe, menguada y empírica" (Ibíd.: 16-17).

Uno de los argumentos que se esgrimía para justificar este imaginario era que los indígenas, al no ser consumidores no aportaban a la "necesaria" activación económica del país. De manera sistemática y reiterativa, "los indios, fueron simbolizados en torno a su falta de consumo de los productos de la industria nacional" (Clark, 1999: 116). Así, por ejemplo, en el Primer Congreso de Industriales, en el año de 1935, el delegado Roberto Levy mencionó:

"El indio produce, produce y produce, pero no consume; no tiene necesidades, porque no se le ha enseñado a utilizar los programas de la civilización y a consumir para que aumente también su producción, y salga de ser máquina que no consume sino que sea hombre. El día que veamos las

10 Kim Clark señala que si bien los indigenistas participaron de manera importante tanto en debates públicos acerca del papel y la posición de los indios en la sociedad nacional y mantuvieron posiciones administrativas influyentes, no siempre tuvieron éxito en la aplicación de las políticas, dada la crisis económica experimentada por el Ecuador desde la década de 1920 hasta 1940 (Clark, 1999: 114-115), “...es posible, por tanto, que los indigenistas fueran más importantes en la construcción de imágenes de los indios que en llevar a cabo políticas reales de incorporación" (Ibíd.).

11 Si bien los orígenes del indigenismo en el Ecuador pueden hallarse a finales del siglo XIX, cuando se denunciaba la problemática indígena con la intensión de diseñar políticas proteccionistas que frenaran el avance de los latifundios sobre las tierras indígenas (Figueroa, 1997), es en los años 20 y sobre todo en los años 30s que estas ideas se configuran como una corriente de pensamiento y toman protagonismo dentro de ciertos círculos intelectuales y políticos del país. 
indias con zapatos de charol, con medias de seda, vestidos y sombreros elegantes, paseándose por las calles de Ambato del brazo de un indio, bien vestido, ese día será para la historia de la economía nacional una bendición, porque ganaríamos para nuestra industria un millón y medio o dos millones de nuevos consumidores para nuestras industrias y darían a nosotros y a ellos nueva forma de trabajo y de vida" (en Ibarra, 2003: 280) ${ }^{12}$.

Con el objetivo de refutar estos estereotipos, el indigenismo llevó a cabo un conjunto de estudios científicos detallados sobre las condiciones biológicas, de nutrición, higiene y salud de las poblaciones indígenas. A nivel metodológico, estas investigaciones, partían de una perspectiva netamente cuantitativa, tendiente a "medir y cuantificar las formas de la diferencia representadas por los indios" (Clark, 1999: 112). Se concluyó que las características de los indios como la pasividad, la melancolía y el aspecto vegetativo, eran el resultado de una historia de opresión que se había incorporado en su naturaleza biológica; por lo que al remover estas condiciones, dejarían atrás estas características (Ibíd.). Algunos indigenistas, como Antonio Santiana, aseguraban, por ejemplo, que los hábitos alimenticios a los que los indígenas se han visto obligados a optar a lo largo de siglos, en los que había mucho carbohidrato y poca proteína y albumina, si bien aportaban a su admirable fuerza y resistencia física, debilitaba su sistema nervioso, adormeciendo finalmente la inteligencia (Santiana, 1941). En este mismo sentido, Pablo Arturo Suárez mencionaba al respecto:

"Desgraciadamente, sobre el indio actual pesa una larga cadena de males varios: la influencia degenerativa de una raza que va inferiorizándose a través de sus hijos: la fuerza inerte de la rutina, la subalimentación, las toxinas y enfermedades que han minado su fuerza espiritual y física, creando el tipo asténico [un tipo de temperamento] y caduco. La vida exclusivamente vegetativa durante siglos, ha apagado toda luz espiritual y ha mantenido la mente del indio en una penumbra soporosa y aletargante" (Suárez 1942: 62).

Paradójicamente, a pesar que los estudios indigenistas pretendían refutar los estereotipos acerca de los indígenas, terminaron naturalizando algunos de ellos. Esto se debió, fundamentalmente, a las premisas evolucionistas, esencialistas y biologicistas que subyacen en su pensamiento, al punto que "se propuso que estos grupos habían evolucionado en direcciones diferentes, con diversas esencias profundas. Subyace la idea de cada grupo como un reservorio genético cerrado: los blancos y los indios, dos razas enteramente separadas" (Clark, 1999: 118). De tal manera, a pesar que consideraban que las características del indígena podían y debían ser cambiadas, contribuyeron a la naturalización de una imagen del indígena como un grupo separado "con rasgos distintivos de raíces biológicas, y con una identidad esencial que era transmitida a través de generaciones por medios biológicos" (Ibíd.: 122).

Desde esta perspectiva, el Estado debía plantear acciones concretas sobre las condiciones materiales del indígena para que éste cambie, y así, incorporarlo eficazmente al desarrollo nacional. En particular, se planteaba poner énfasis en la alimentación, la higiene o la infraestructura de sus hogares (Clark, 1999). A nivel pragmático, a pesar que el indigenismo exhortó la creación de políticas particulares para los pueblos indígenas, estas políticas fueron "protectoras, porque se concebía al indígena como un individuo económica y socialmente débil un menor de edad, y corporativas, porque era indispensable la integración total de los indios bajo la forma de ciudadanía en la vida económica y social de cada país" (Rivera, 1998: 59), al mismo

12 Posteriormente, dentro del contexto de las reforma agrarias (1964 - 1972) es posible evidenciar cómo estas representaciones sobre el indígena vuelven a activarse. Mediante un conjunto de artículos en revistas y notas de prensa, los sectores terratenientes, en particular la Cámara de la Ganadería, llevó a cabo una campaña de desprestigio a las reformas agrarias, que se sostenía, entre otros imaginarios, en la idea de la existencia de dos grupos raciales con diferentes capacidades productivas: "un grupo racial, capaz de producir, ser eficiente, y hacer que la tierra cumpla su función social, asociado con el futuro y con un mejor presente. Otro, improductivo, pre-moderno, incapaz de contribuir al desarrollo nacional, es asociado con el pasado y el deterioro" (Pallares, 1999: 166). 
tiempo que excluía la participación de los indígenas de dichas políticas en su diseño y ejecución (Chávez, 2008). Por lo tanto, el indigenismo constituye una visión paternalista, asimilacionista, esencialista y homogenizante que en la primera mitad del siglo XX:

Resultó ser el instrumento más adecuado para la construcción de la tan ansiada nación blancomestiza, ya que permitió transitar de acciones explícitamente destructivas de las culturas de los pueblos indígenas, hacia la adopción de un proyecto de largo aliento, basado en el efecto absorbente y asimilador de la cultura nacional dominante (Rivera, 1998: 60).

Posteriormente, entre los años 70s y 80 s, se consolida una nueva corriente de pensamiento, conocida como "neoindigenismo"13. Su contribución más importante, radica en su abierta oposición al determinismo racial, concepción que interpretaba las diferencias culturales como una cuestión de "raza", distanciándose así incluso de las premisas biologicistas del indigenismo tradicional. De esta manera, "el neoindigenismo da un vuelco a este discurso, intentando superar el determinismo racial en el pensamiento acerca de la sociedad y la cultura en el Ecuador" (Ribadeniera, 2001: 76). De acuerdo con autores como José Figueroa (1996), los discursos neoindigenistas contribuyeron a que, en ciertos sectores de la sociedad, se dé un giro hacia una valoración positiva del indígena.

En síntesis, el neoindigenismo constituye una corriente académica, aparentemente progresista y crítica del indigenismo tradicional-sobre todo de sus intereses asimilacionistas-que se caracteriza por "postular la pluralidad o diversidad sociocultural de las formaciones nacionales a base de un sobredimensionamiento de la civilización india como proyecto societal global" (Rivera, 1998: 60). No obstante, si bien "a diferencia del indigenismo de los años treinta, resaltó los aspectos de la diferencia, del reconocimiento de la pluralidad y de la recomposición étnica" (Figueroa, 1996: 206), y trascendió el biologicismo; el neoindigenismo partió de una conceptualización esencialista de cultura que concibe a las sociedades indígenas como culturalmente puras y estáticas; al tiempo que las idealiza en términos de una superioridad moral, espiritual y cultural. De tal manera, “...si en el indigenismo paternalista prevalecía una noción de indio atrasado, decadente, irracional e incivilizado, en esta nueva versión aparentemente radical, aflora la idea del buen salvaje, solidario, fraterno, milenario, apacible y aunque radical, participativo en los ámbitos de la sociedad y estado nacional" (Ibíd.: 61).

Dentro de este complejo panorama en el que el monopolio de la representación se encontraba en manos de las élites blanco-mestizas, quienes a través de diversos regímenes de representación intentaron definir las supuestas características de los "otros" indígenas, estos grupos racializados subalternos emprendieron complejos procesos organizativos, políticos e identitarios, con el fin de conquistar derechos que les fueron negados por siglos, en particular, el derecho de poder hablar por sí mismos, ser agentes de su propia identidad y disputar el poder de los imaginarios que se habían creado sobre ellos. En este proceso, las reivindicaciones étnicas-identitarias de los movimientos indígenas, sus discursos y acciones, han sido fundamentales.

\section{Los discursos y acciones etnicistas de los movimientos indígenas}

Si bien, los primeros movimientos indígenas ecuatorianos se remontan a los años 30s-40s del siglo XX, es desde finales de los años 60 s que estos movimientos construyen un discurso de corte etnicista que viene a constituirse en el principal argumento de sus demandas y de su identidad como grupo. Este discurso "recogía como punto de fuerza el pasado histórico de la Conquista

13 Los orígenes del neoindigenismo a nivel latinoamericano pueden encontrarse en los encuentros Barbados I y Barbados II (1971 - 1977 respectivamente), mismos que "representaron un hito al incorporar por primera vez a líderes indígenas de la época como interlocutores válidos en el tratamiento de la problemática indígena (...) Además se consideró necesario desarrollar una organización indígena política propia y auténtica, así como desarrollar una ideología consistente y clara, cuyo elemento aglutinador sea la propia cultura” (Chávez, 2008: 232). 
española cuyos abusos y violencias revalidarían las luchas indígenas del presente en contra de los blancos explotadores, siendo éstos últimos los terratenientes y la sociedad nacional en general" (Cervonne, 1997: 3). En ese sentido, desde un inicio el discurso étnico de los movimientos indígenas definió a los blanco-mestizos como su afuera constitutivo.

En 1973 surge la organización indígena ECUARUNARI ${ }^{14}$. A diferencia del discurso estatal de aquel entonces, que veía a los indígenas principalmente como "campesinos", o del discurso terrateniente que los veía como "minifundistas", reduciéndolos a una dimensión económica, la ECUARUNARI destacó y puso énfasis en su condición étnica, oficializando internamente la autodenominación de cultura indígena como fundamento para la consecución de sus derechos (Pallares, 1999). Desde entonces, "si bien la identidad económica campesina no desapareció, fue la indianidad, y no el campesinismo lo que se convirtió en la base identitaria del movimiento indígena contemporáneo" (Ibíd.: 170).

El discurso de esta organización se estructuró, principalmente, en base a una crítica al capitalismo, entendido este no solo como un sistema económico sino también como un sistema cultural, que por su tendencia impositiva y omnipresente es "culpable de la aculturación de los indígenas y de la pérdida de los valores culturales, especialmente de los jóvenes indígenas" (Ibíd.: 169). Ante esta amenaza cultural "la recuperación de las formas y cultura tradicionales y el rescate y mantenimiento de la indianidad fueron un objetivo importante desde el inicio de la organización" (Ibíd.). De tal manera, la ECUARUNARI apeló a las ideas de una supuesta esencia, pureza y autenticidad de la cultura indígena, que se encontraría en las tradiciones y prácticas amenazadas por las fuerzas homogeneizantes del capitalismo.

En 1986 se crea la Confederación de Nacionalidades y Pueblos Indígenas del Ecuador, CONAIE, la organización indígena más grande del país ${ }^{15}$. Su discurso gira en torno a los conceptos de nacionalidad, territorio, plurinacionalidad e interculturalidad (Altmann, 2014). La nacionalidad, según la propia CONAIE (2004: 116), "es la autodefinición de un grupo étnico", la misma que se definiría por "un mismo origen, una historia común, idiomas propios [y] nuestras propias leyes, costumbres y creencias y formas de organización social, económica y política en nuestros territorios" (Ibíd., 2001: 2). Dentro de las nacionalidades hay pueblos que comparten lo anteriormente mencionado pero se diferencian entre sí "porque comparten un sentido de pertenencia local y una propia forma de vivir su cultura [...] ocupan un territorio definido, y tienen aspiraciones comunes" (Ibíd.: 3). De tal manera, según la CONAIE, "los indígenas del Ecuador se organizan en nacionalidades que, en el caso de la nacionalidad más grande, la de los Kichwa de la Sierra, se subdividen en Pueblos" (Kaltmeier, 2007: 202).

Por su parte, el territorio hace referencia a la administración autónoma de las tierras, "mediante instituciones ancestrales del pueblo que ahí vive" (ECUARUNARI/ CONAIE, 1989: 11). Constituye por tanto una "delimitación simbólica de fueros étnicos al interior de los cuales los grupos indígenas, en este caso las nacionalidades indígenas, se autogobernarían" (Cervonne, 1997: 15). Muy relacionado al concepto anterior, la plurinacionalidad se refiere a "un sistema de autogobiernos territoriales, una extensión de la democracia, sobre todo donde concierne el control de recursos, la pluralidad jurídica y la oficialización de las lenguas indígenas" (CONAIE, 2007: 5). La CONAIE (2001: 4-5) contrapone el Estado Plurinacional a lo que llaman "Estado Uninacional", definido por la exclusión y el racismo. Así, el Estado plurinacional es definido como "anticolonialista, antiimperialista y antisegregacionista". Cabe mencionar que la plurinacionalidad es considerada como el "máximo objetivo" de la CONAIE. Por último, la

14 Organización de tercer grado que agrupa a gran parte de los pueblos indígenas de la sierra del Ecuador.

15 La CONAIE está conformada por las organizaciones regionales: ECUARUNARI, CONFENAIE (Confederación de Nacionalidades Indígenas de la Amazonía Ecuatoriana) y CONAICE (Confederación de Nacionalidades y Pueblos Indígenas de la Costa Ecuatoriana). La CONAIE es identificada como una organización con propuestas de izquierda, su brazo político es el partido Pachakutik surgido en 1995, de tendencia socialista. 
interculturalidad es una condición fundamental de un Estado plurinacional. Esta se construye mediante la apertura hacia los grupos excluidos y la inclusión de la diferencia bajo el lema de "unidad en la diversidad" (Ibíd., 2001).

Como se puede apreciar, el discurso de la CONAIE propuso un sistema de categorías étnicoidentitarias (pueblos y nacionalidades) definiendo, a su vez, las condiciones o características que debe tener un grupo social para ser considerado como tal. Es importante acotar que, como lo menciona Olaf Kaltmeier, "estos conceptos identitarios-territoriales no son conceptos tradicionales o primordiales, sino construcciones recientes del movimiento indígena" 16 (Kaltmeier, 2007: 202).

Además, cabe observar que las demandas clasistas (administración autónoma de las tierras, sistema de autogobiernos territoriales, control de recursos, etc.) fueron subordinadas a las demandas de tipo étnico-culturales y "se impuso un entendimiento de las diferencias de clase como producto de desigualdades culturales. Es más, lo cultural fue entendido como étnico, cambiando la interpretación de una exclusión cultural y -en consecuencia- de la demanda de interculturalidad" (Altmann, 2014: 12). En ese sentido, en el discurso de la CONAIE es posible identificar lo que autores como Guillermo Bustos (2007) denominan "la politización de lo étnico".

Por otro lado, es importante mencionar que la CONAIE, en la década de los 90, protagonizó una serie de masivos levantamientos y protestas frente al Estado ecuatoriano, cargados de un profundo contenido simbólico y ritual, y en base a su discurso etnicista (Cervonne, 1997). Estas protestas remarcaron las fronteras étnicas entre indígenas y blanco-mestizos, pero esta vez no desde el grupo étnico hegemónico (como había venido siendo desde la Colonia) sino desde el grupo étnico subalternizado. Por ejemplo, en el levantamiento de junio de 1990, considerado el mayor levantamiento indígena de la historia ecuatoriana, y que fue realizado en la fecha de celebración del Inti Raymi (la fiesta más importante dentro de la cosmovisión indígena) se anunció el regreso del Pachakutik, que indica la vuelta o el retorno al tiempo de los indígenas. Igualmente, el levantamiento de 1992 en Pastaza coincidió con la celebración oficial de los quinientos años del denominado "encuentro entre dos mundos" (Chávez, 2008).

De tal manera, tanto el discurso como las acciones etnicistas llevadas a cabo por los movimientos indígenas partieron de un ejercicio de racialización esencialista que recogía la categorización colonial de "indígenas" y "blanco-mestizos" como grupos separados y étnicamente opuestos, es decir con características y rasgos esencialmente diferentes, pero esta vez valorando a cada uno de estos grupos de manera distinta.

De acuerdo a varios autores, los levantamientos indígenas de la década del 90 "constituyeron verdaderos quiebres de los imaginarios nacionales respecto a los indios (...) evidenciaron cambios profundos en las percepciones que se tenían sobre los movimientos indígenas" (Rivera, 1998: 62). En ese sentido:

\footnotetext{
"Todos los logros de las luchas indígenas adquieren una eficacia simbólica por ser no solo respuestas a las necesidades del sector campesino indígena sino también pruebas fehacientes de que ciertos imaginarios construidos alrededor del indio durante 500 años han sido errados producto de la discriminación racista. La sola existencia de líderes indígenas educados y productores de sus propios discursos de poder es en sí una demostración ante la sociedad nacional de que los indios ya no son brutos e ignorantes" (Cervone, 1997: 4).
}

16 De acuerdo a Xavier Albó, el desarrollo de las categorías de" nacionalidad" y "pueblo", dentro de los movimientos indígenas ecuatorianos, empieza en los años 70s y tuvo su primera expresión en el nombre de la CONFENIAE. El concepto "nacionalidad" fue resemantizado a partir del concepto homologo que se encuentra en el comunismo soviético (Becker, 2008: 173). Albo al respecto menciona: "destaca el trabajo del antropólogo ruso Yuri Zubritski que en los años 1970 procuró becas en Rusia a sus alumnos ecuatorianos, entre los cuales se encontraron Ileana Almeida, Nina Pacari y Auki Tituaña. Sobre todo Almeida popularizó la teoría marxista-leninista de desarrollo que ubica la nacionalidad como etapa entre un sistema de tribus y la constitución de una nación que finalmente se transforma en estado" (Albó, 2009: 211). 
En efecto, la participación de intelectuales y activistas indígenas en medios de comunicación así como la creación o utilización de espacios y contra-esferas públicas subalternas (foros, libros, revistas, festivales de cine independientes) produjeron que "la esfera pública oficial sea modificada y que, si bien perduraran imágenes construidas en el pasado, estas convivan con nuevas representaciones y auto-representaciones" (De la Torre \& Hollenstein, 2010: 9). Así, los discursos coloniales, liberales, desarrollistas, indigenistas, entre otros, se vieron cuestionados por los propios movimientos indígenas, quienes se consolidaron como un nuevo agente discursivopolítico con capacidad de interpelar, cuestionar y contradecir tales discursos, al mismo tiempo que lograron posicionar sus propios discursos dentro del campo de las representaciones dominantes que sobre ellos se habían construido. Por lo tanto, es posible afirmar que a través de estas acciones y discursos etnicistas, los indígenas lograron transcender la condición de subalternidad en su dimensión identitaria.

Paralelamente a estos procesos, varias comunidades indígenas a nivel local entraron en un "proceso de etnogénesis en el que la cultura es reificada para poder llegar a establecer elementos concretos, 'nuestras danzas, nuestra música, nuestra vestimenta' que la re-presenten" (Cervonne, 1999: 10). Así por ejemplo, Emma Cervone evidencia que, en la parroquia de Tixán ${ }^{17}$, la organización indígena de segundo grado "Inca Atahualpa", a través de varias fiestasrituales "llegó a definir el traje típico de la zona, dejando de lado la heterogeneidad y variedad existente y emprendiendo un proceso de folklorización que, aunque supuestamente tendiente al fortalecimiento de la construcción de la identidad indígena, podría poner en peligro los mismos fundamentos de la lucha étnica: el respeto a la diferencia" (Ibíd.: 9). Las investigaciones etnográficas de esta autora, evidencian que el idioma kichwa y la vestimenta antigua-tradicional fueron los principales elementos que las comunidades indígenas a nivel local establecieron para autodefinirse como indígenas. No obstante, este proceso mantiene notables semejanzas con el proceso de homogenización que caracterizó a la construcción de las identidades nacionales:

"Las lógicas internas de construcción de esas micro-identidades de la diversidad parecen ser las mismas de la modernidad. (...) el énfasis sobre los contenidos étnicos-culturales ha sido adoptado de los mismos criterios usados para forjar las identidades nacionales. En este sentido la etnicidad toma cuerpo en el discurso político para definir, a través de elementos visibles y concretos (el idioma, la vestimenta, la música, etcétera), el "nosotros" y el "otros" de las sociedades modernas y las fronteras simbólicas que los separan (IbId.: 21).

De tal manera, si bien la identidad indígena ha llegado a ser un instrumento simbólicopolítico muy eficaz, que ha sido utilizado por los grupos étnicos subalternizados para su propia defensa y autoafirmación social, así como para la consecución de sus derechos fundamentales; en su proceso de consolidación, sobre todo dentro de sus movimientos y organizaciones sociales, se han incorporado y reproducido premisas, como la lógica de la homogenización interna e ideas esencialistas de su cultura, que podrían llegar a atentar la diversidad cultural de los grupos que se consideran o son considerados como indígenas ${ }^{18}$.

Esta reproducción homogenizante y esencialista en las lógicas de identidad se debe a la continuidad de la colonialidad (del poder, del saber y el ser) que todavía sigue caracterizando a las sociedades latinoamericanas. Como bien lo afirma Rita Segato (2011: 23): "Ese enyesamiento en posiciones de identidad es también una de las características de la racialización, instalada por el proceso colonial moderno, que empuja a los sujetos a posiciones fijas dentro del canon binario aquí constituido por los términos blanco - no-blanco".

17 Provincia de Chimborazo, sierra centro del Ecuador.

18 Es importante acotar que las identidades indígenas que han logrado establecerse como oficiales tanto en la institucionalidad estatal (y promovidas por ésta) como en los campos discursivos y mass mediáticos, han sido construidas y promovidas, principalmente, por los líderes y otras élites indígenas, y no corresponden ni abarcan totalmente los diversos y complejos procesos de reconstrucción identitaria de todos los grupos que se autodefinen como indígenas. 
Por último, es importante revisar brevemente cual ha sido la relación que se ha construido entre los movimientos indígenas y el Estado ecuatoriano a partir de las acciones y discursos etnicistas de estos movimientos. En primer lugar, cabe mencionar que ante las movilizaciones indígenas de los 90s, el Estado se vio en la obligación de emprender un intenso proceso de institucionalización de sus demandas. Este proceso comenzó con la creación de la Dirección Nacional de Educación Intercultural Bilingüe (DINEIB) en 1988. Después, en 1996, se inauguró el Ministerio de Asuntos Étnicos. Dos años después se creó el Consejo Nacional de Pueblos y Nacionalidades del Ecuador, CODENPE, entidad pública de representación de los pueblos autodefinidos como nacionalidad indígenas. En 1998 se inició el Proyecto de Desarrollo de los Pueblos Indígenas y Negros del Ecuador, PRODEPINE. La primera etapa de este proceso culminó con la constitución de 1998, que define al país como pluricultural y reconoce una serie de derechos colectivos de los pueblos y nacionalidades.

En efecto, la constitución de 1998, "ha representado un hito importante en la redefinición de la relación indígenas-Estado-sociedad civil, así como en la redefinición de la identidad nacional desplazándola desde la ideología del mestizaje al paradigma de la diversidad multicultural" (Cervone, 2009: 200). A partir de dicha Constitución, el Estado ecuatoriano se ha caracterizado por el desarrollo de políticas y discursos multiculturales hacia los indígenas y demás grupos étnicos que lo componen. No obstante, cabe precisar que bajo el multiculturalismo,

"la diversidad es regulada más que incorporada, definiendo límites y jurisdicciones muy específicos, entre los cuales cada uno de los sistemas diversos puede operar [...] En el caso ecuatoriano el pasaje de la retórica del mestizaje a la retórica del multiculturalismo oficial presenta una continuidad en la manera en que se plantea, por parte del Estado y de las élites políticas, contener, administrar y fagocitar las demandas del movimiento indígena; se trata de la "etnofagia" planteada por DíazPolanco (2006)" (Ibíd.: 205 - 210).

Nos encontramos, por tanto, frente a la "paradoja de que ahora es el propio Estado quien apunta a la 'etnización' del movimiento indígena" (Kaltmeier, 2007: 207). Esta aparente paradoja responde a un nuevo proceso de colonización en que el Estado, aprovechando las premisas esencialistas y homogenizantes de los discursos de los propios movimientos indígenas, administra la diferencia cultural, la define desde una perspectiva funcional a sus intereses, al mismo tiempo que la parcializa, la despolitiza y la desmoviliza. Tal como lo menciona Mario Rufer (2012: 28):

“...en la acción por la cual son reconocidos esos 'otros internos', son también movidos hacia una parcialidad diferenciada y productora de otredad; y forman parte de un Estado-nación que en el propio proceso por el cual reconoce y otorga, continúa ejerciendo el poder de la mirada legislativa, administrando subjetividades/sujeciones, y extendiendo su soberanía".

De tal manera, a nivel estatal se ha transcurrido de un marcado paternalismo tendiente a "blanquear" a las poblaciones indígenas, a un multiculturalismo que al mismo tiempo que las incluye, las administra, les impone límites y las desmoviliza. Ante este nuevo panorama, cabe preguntarse si en realidad podemos hablar de una etapa "post-subalterna" de la identidad indígena o más bien nos encontramos frente a una renovada etapa de colonialidad, en la que la subalternidad identitaria es redefinida en su forma pero mantiene, sin mayores cambios, su fondo. 


\section{Conclusiones}

El control monopólico y la manipulación de la representación sobre el indígena se ha constituido en un ejercicio simbólico-discursivo de central importancia dentro del proceso de hegemonización de los grupos dominantes del país y la concreción de sus intereses y finalidades. En el siglo XX, y con el objetivo de construir la identidad nacional ecuatoriana, los grupos blanco-mestizos en el poder construyeron varios relatos sobre el "ser indígena", definiendo sus rasgos y características, que en el marco de su monopolio sobre los medios de comunicación, se constituyeron en regímenes de representación que impusieron la condición de subalternidad identitaria a los grupos indígenas.

Dentro de este adverso panorama, las poblaciones indígenas emprendieron complejos procesos organizativos con el fin de ser agentes de su propia identidad y con ello plantear una serie de demandas al Estado y a la sociedad ecuatoriana en general. En este proceso, construyeron discursos de corte etnicistas, utilizaron contra-hegemónicamente los medios de comunicación y llevaron a cabo varias movilizaciones masivas con un complejo contenido simbólico y ritual, logrando con ello posicionar sus discursos dentro del campo de las representaciones sociales dominantes que sobre ellos se ha creado, y así disputar el sentido sobre el "ser indígena".

No obstante, paradójicamente, estos discursos y acciones etnicistas incorporaron premisas que han estado presentes en los mismos regímenes de representación que impusieron su condición de subalternidad, como la premisa de la racialización escencialista o la lógica de la homogenización interna, premisas que pueden estar creando nuevos patrones de subalternizacion dentro de las propias dinámicas identitarias de quienes se consideran o son considerados indígenas.

Además, el Estado ha aprovechado estas premisas para, desde una perspectiva multiculturalista, administrar la diferencia cultural, definirla desde una perspectiva funcional a sus intereses, y al mismo tiempo despojarla de su contenido político, movilizador y liberador. En ese sentido, a pesar de la aparente transcendencia de la condición de subalternidad identitaria, existe una continuidad de la colonialidad del poder y del ser dentro de los procesos de construcción de la identidad étnica de ciertos sectores del movimiento indígena. 


\section{Bibliografía}

Almeida, José. 1990, "Indios y campesinos del siglo XX”, en: Nueva Historia del Ecuador, vol. 10, Corporación Editora Nacional, Quito.

Altmann, Philipp. 2014, "Una breve historia de las organizaciones del Movimiento Indigena del Ecuador”, en: Revista Antropología. Cuadernos de Investigación, No. 12, PUCE, Quito pp. 1-17.

Barker, Chris. 2003, Televisión, globalización e identidades culturales, Paidós, Buenos Aires.

Bretón, Víctor. 2007, "A vueltas con el neo-indigenismo etnófago: la experiencia Prodepine o los límites del multiculturalismo neoliberal”, en: Iconos. Revista de Ciencias Sociales, No. 29, FLACSO, Quito. pp. 95-104.

Botero, Luis. 2011, Para no ser una carga. Pasado y presente de las comunidades indígenas del Chimborazo. Riobamba. Manos Unidas ediciones.

Buschges, Christian, 2007, La etnicidad como recurso político. Etnizaciones y de-etnizaciones de lo político en América Andina y Asia del Sur, en: Buschges, Christian y Guillermo Bustos (Comps.) Etnicidad y poder en los países andinos, Corporación Editora Nacional, Quito.

Cervone, Emma. 2009, "Los desafíos del multiculturalismo", en: Martínez Novo, Carmen (Ed.) Repensando los Movimientos Indigenas, FLACSO, Quito.

1997, El retorno de Atahualpa. Etnicidad y movimiento indígena en Ecuador, Pontificia Universidad Católica, Quito, en línea: http://lasa.international.pitt.edu/LASA97/cervone.pdf

Chávez, Leopoldo. 1943, "Discurso del ministro de Previsión Social en la Inauguración de las Labores del Instituto Indigenista del Ecuador", en: Revista Previsión Social. No. 14.

Chávez, Gina. 2008, "Proteccionismo humanista: retórica y praxis del neo indigenismo en el Ecuador, en: García, Fernando (Comp.) Identidades, etnicidad y racismo en América Latina, FLACSO, Quito.

Clark, Kim. 1999, "La medida de la diferencia: las imágenes indigenistas de los indios serranos en el Ecuador (1920 a 1940)", en: Cervone, Emma y Fredy, Rivera (Eds.) Ecuador Racista. Imágenes e Identidades, FLACSO, Quito.

CONAIE. 2007, "La CONAIE frente a la Asamblea Constituyente", en línea: http://www.cebem.org/cmsfiles/ archivos/principios-lineamientos-conaie.pdf

2004, Propuesta de Ley de Biodiversidad, CONAIE, Quito, pp. 116-117.

2001, "Proyecto Político de las Nacionalidades y Pueblos del Ecuador", en línea: http://www.conaie.org/ congresosde-la-conaie/ii-congreso-ed-la-conaie/99-proyecto-politico-de-las-nacionalidades-y-pueblosdelecuador?format $=$ pdf.

ECUARUNARI/CONAIE. 1989, "Lineamientos políticos generales del movimiento indígena en el Ecuador", en: ECUARUNARI, FENOC, ALAI (Eds.) Nuestra voz, nuestra cultura, ECUARUNARI/FENOC/ ALAI, Quito.

De la Torre, Carlos y Hollenstein, Patric. 2010, Los medios de comunicación y la población afroecuatoriana Periodo considerado: 1996-2009, Proyecto Regional "Población afrodescendiente de América Latina", Panamá.

Díaz-Polanco, Hector. 2006, Elogio de la diversidad. Globalización, multiculturalismo y etnofagia, Ediciones Siglo XXI, México.

Dubet, Francois. 1987, "De la sociología de la identidad a la sociología del sujeto", en: Revista Estudios Sociológicos. Vol. 7. $\mathrm{N}^{\circ} 21$, pp. 519-545.

Fraga, Eugenia. 2013, “El problema de la identidad en los estudios poscoloniales”, en: Revista Astrolabio. № 11, pp. 386- 410.

Figueroa, José. 1996, "Comunidades indígenas: artefactos de construcción de la identidad étnica en los conflictos políticos del Ecuador contemporáneo", en: Revista Colombiana de Antropología, Vol. XXXIII, Bogotá, pp. 185-219.

Guerrero, Andrés. 1998, “Ciudadanía, frontera étnica y compulsión binaria”, en: Revista ICONOS, No 4, FLACSO, Quito.

1993, "La Desintegración de la Administración Étnica en el Ecuador", en: Almeida, José (Coord.) Sismo Étnico en el Ecuador, Ediciones Abya Yala, Quito.

1994, "Una imagen Ventrilocua: El discurso liberal de la "desgraciada raza indígenas" a fines del siglo XIX", en Muratorio, Blanca (Ed.) Imágenes e imagineros. Representaciones de los indígenas ecuatorianos, siglos XIX $y X X$, FLACSO, Quito.

Hall, Stuart. 2010, Sin Garantias: Trayectorias y problemáticas en Estudios Culturales, UASB, Quito. 
2003, “¿Quién necesita 'identidad’”, en: Hall, Stuart y Paul du Gay, Cuestiones de identidad cultural, Amorrortu, Buenos Aires, pp. 13-39.

Ibarra, Hernán. 2016, “Génesis y significado de la reforma agraria de 1964”, en: Rhon, Francisco y Carlos Pástor (Eds.) 50 años de Reforma Agraria. Cuestiones pendientes y miradas alternativas, Ediciones la Tierra, Quito.

2003, "La identidad devaluada de los Modern Indians", en Pachano, Simón (Ed.) Antología Ciudadanía e identidad, FLACSO, Quito.

1999, "Intelectuales indígenas, neoindigenismo e indianismo en el Ecuador", en: Revista Ecuador Debate. Etnicidades e identificaciones, No. 48, CAAP, Quito, pp. 71-94.

Kaltmeier, Olaf. 2007, “¿Politización de lo étnico y/o etnización de lo político? El campo político en el Ecuador de los años noventa", en: Buschges, Christian y Guillermo, Bustos (Comp.) Etnicidad y poder en los países andinos, Corporación Editora Nacional, Quito.

Marcús, Juliana. 2015, Apuntes sobre el concepto de identidad. Intersticios, en: Revista Sociológica de Pensamiento Crítico, $\mathrm{N}^{\circ}$. 1, Vol. 5, pp. 107-114.

Marzal, Manuel. 1998, Historia de la Antropología, Abya Yala, Quito.

Muratorio, Blanca. 2003, "Discursos y silencios sobre el indio en la conciencia nacional", en: Pachano, Simón (Comp.) Antología: ciudadania e identidad, FLACSO, Quito.

1994, "Discursos y silencios sobre el indio en la conciencia nacional", en: Muratorio, Blanca (Ed.) Imágenes e Imagineros. Representaciones de los Indígenas Ecuatorianos, Siglos XIX y XX, FLACSO, Quito.

Pallares, Amalia. 1999, Construcciones raciales, reforma agraria y movilización indígena en los años setenta, en: Cervone, Emma y Fredy Rivera (Eds.), Ecuador Racista. Imágenes e Identidades, Quito, FLACSO.

Quijano, Aníbal. 2000, "Colonialidad del poder, eurocentrismo y América Latina”, en: Lander, Edgardo (Comp.) Colonialidad del saber. Eurocentrismo y ciencias sociales. Perspectivas Latinoamericanas, CLACSO, Buenos Aires, pp. 201-246.

Ribadeniera, Catalina 2001, El racismo en el Ecuador contemporáneo. Entre la modernidad y el fundamentalismo étnico, Abya Yala, Quito.

Rivera, Fredy. 1998, "Los indigenismos en Ecuador: de paternalismos y otras representaciones", en: Revista América Latina Hoy. No 19, pp. 57-63.

Rufer, Mario. 2012, "El habla, la escucha y la escritura. Subalternidad y horizontalidad desde la crítica poscolonial", en: Corona Berkin, Sarah y Olaf, Kaltmeier (Cords.) En diálogo. Metodologías horizontales en Ciencias Sociales, Gedisa, México.

Said, Edward. 2004, Orientalismo, Editorial Sudamericana, Barcelona.

Santiana, Antonio. 1941, La distribución Pilosa como carácter racial: su modalidad en los indios de Imbabura, Ecuador, Universidad Central del Ecuador, Quito.

Segato, Rita. 2011, "Género y colonialidad. En busca de claves de lectura y de un vocabulario estratégico decolonial", en: Bidaseca, Karina y Vanesa, Vázquez Laba (Comps.) Descolonizando el feminismo desde (y en) América Latina, Godot, Buenos Aires, pp. 17-48.

Spivak, Gayatri. 2003, “Puede hablar el subalterno?”, en: Revista Colombiana de Antropología. Vol. 39, pp. 297- 364.

Suárez, Pablo Arturo. 1943, Contribución al Estudio de la Alimentación y Nutrición del Indio de Otavalo, Universidad Central del Ecuador, Quito. 